Article

\title{
Optimization of the Calcium Alginate Capsules for Self-Healing Asphalt
}

\author{
Shi Xu ${ }^{1, *}$, Amir Tabaković ${ }^{1,2,3}$, Xueyan Liu ${ }^{1}$, Damian Palin ${ }^{1,4}$ and Erik Schlangen ${ }^{1}$ \\ 1 Civil Engineering and Geosciences, Delft University of Technology, Delft 2628CN, The Netherlands; \\ amir.tabakovic@dit.ie (A.T.); x.liu@tudelft.nl (X.L.); D.Palin@tudelft.nl (D.P.); \\ Erik.Schlangen@tudelft.nl (E.S.) \\ 2 Research Enterprise and Innovation, Technological University Dublin, Dublin D07EWV4, Ireland \\ 3 School of Civil Engineering, University College Dublin, Dublin D04K3H4, Ireland \\ 4 Materials Science and Engineering, Cornell University, Ithaca, NY 14853, USA \\ * Correspondence: xushi891011@gmail.com; Tel.: +31(0)-15-27-85944
}

Received: 3 December 2018; Accepted: 28 January 2019; Published: 30 January 2019

Featured Application: This self-healing technology for asphalt pavements has the potential to greatly disrupt asphalt production methods (which have been stable over the past 100 years). This paper presents a development process of 'calcium-alginate microcapsules encapsulating an asphalt bitumen rejuvenator'. The encapsulated rejuvenator is released when required (on demand) which rejuvenates the aged binder. Once crack is initiated and starts propagating it encounters a microcapsule, energy at tip of the crack opens the microcapsule, releasing the rejuvenator (healing agent). The rejuvenator will infuse into the aged binder soften it, allowing to flow, two broken edges to get into a contact and seal the crack, i.e., repair the damage. This self-healing system has the potential to double the life span of roads, greatly improving road performance while reducing costs. By advancing self-healing technology and applying it to the road industry, the self-healing technology presents an opportunity to revolutionise road design and costs, both financial and environmental, associated with the road construction and maintenance processes.

\begin{abstract}
It has been demonstrated that calcium alginate capsules can be used as an asphalt healing system by pre-placing rejuvenator (healing agent) into the asphalt mix and releasing the rejuvenator on demand (upon cracking). This healing mechanism relies on the properties of capsules which are determined by the capsule preparation process. In this study, to optimize the calcium alginate capsules, capsules are prepared using varying Alginate/Rejuvenator (A/R) ratios. Light microscope microscopy and Environmental Scanning Electron Microscope (ESEM) are employed to characterize the morphology and microstructure of these capsules. Thermal stability and mechanical property are investigated by thermogravimetric analysis (TGA) and compressive tests. The testing results indicate that higher alginate content results in smaller diameter and lower thermal resistance, but higher compressive strength. The optimum A/ $R$ ratio of calcium alginate capsules is found to be $30 / 70$. To prove the effectiveness of the optimized capsules, the capsules are embedded in asphalt mortar beams and a bending and healing program is carried out. The effect of capsule shell material on the mechanical response of asphalt mixture is evaluated through three-point bending on the mortar beams embedded with blank capsules (without the healing agent). Aged mortar beams containing alginate capsules encapsulating rejuvenator demonstrate a higher strength recovery after bending tests, which indicates effective healing due to the release of the rejuvenators from the capsules.
\end{abstract}

Keywords: asphalt; rejuvenation; alginate; capsules 


\section{Introduction}

Asphalt concrete is widely used for pavement construction throughout the world. During its service life, the asphalt concrete ages due to environmental effects including oxidation, UV light irradiation and moisture damage, which make it become stiffer with time and gradually lose its original properties [1-4]. As a result, ageing of asphalt leads to an increase of stiffness and brittleness which make it prone to premature failures like cracking and raveling [5].

Although the phenomenon of ageing deteriorates the performance of asphalt pavement, an asphalt rejuvenator, including industrial rejuvenator and oil $[5,6]$, can be used to reverse this process by restoring the lost properties of aged asphalt, i.e., stiffness and self-healing capacity [7]. The asphalt rejuvenator has been successfully used in asphalt recycling [8] and surface course rejuvenation [9]. However, the surface course rejuvenation allows the asphalt rejuvenator to reach no more than $2 \mathrm{~cm}$ of the pavement structure, which means microcracks inside the pavement cannot be healed. Moreover, all these procedures require onsite construction work which leads to traffic restrictions, use of fresh materials and an increase of $\mathrm{CO}_{2}$ emission [10].

As an emerging self-healing technology in asphalt pavement, the capsule healing method provides a solution to the ageing problem, thus prolong the service life of asphalt pavement [5]. Researchers have shown that the inclusion of encapsulated asphalt rejuvenator in an asphalt mix is a promising method to improve the self-healing capacity in asphalt pavement [5]. The intention of the embedded capsules is to deliver encapsulated healing agent into the asphalt pavement, when a crack occurs, the healing agent is released into the microcrack, wets the crack surfaces, diffuses into the aged bitumen, and softens the aged binder, allowing it to flow and eventually heal the crack [10]. The concept of using embedded capsules was first reported by White et al. [11]. White's self-healing concept has been applied to many other materials, including asphalt. Research has been carried out to explore effective rejuvenator delivery system for asphalt pavement, and some encapsulation methods have been investigated, such as epoxy capsules [12] and Melamine-formaldehyde (MMF) capsules [13]. Recently, alginate, a low-cost and environmentally friendly biopolymer that is largely stored in brown algae, has been used as an encapsulation material for asphalt rejuvenator to achieve self-healing in asphalt pavement [14-17]. As an anionic polysaccharide, alginate cross-polymerizes when exposed to a solution containing divalent cations such as $\mathrm{Ca}^{2+}[18]$.

Tabaković et al. [15] successfully used compartmented alginate fibers to encapsulate rejuvenator and proved the effectiveness of this self-healing system on micro-crack healing. However, the rejuvenator content in the alginate fiber compartments was very limited. To improve this situation, $\mathrm{Xu}$ et al. [16] developed a more efficient rejuvenator delivery system using calcium alginate capsules. The prepared capsules had the rejuvenator content of $56 \%$ by volume. These capsules were proved to be able to survive during the asphalt production process and showed a significant healing effect on asphalt mastic samples. The previous research demonstrated that alginate is a positive material for rejuvenator encapsulation thus application in self-healing asphalt [16]. However, the healing mechanism of this capsule healing system relies on the properties of the capsules. A change in diameter, microstructure or rejuvenator content of calcium alginate capsules would result in different thermal and mechanical properties, which largely affect the healing capacity of this capsule healing system. Thus, an optimization of this healing system is needed.

The main objective of this research is to optimize the calcium alginate capsules for the application in self-healing asphalt. In this study, the calcium alginate capsules are prepared with varying $A / R$ ratios, and the thermal stability and mechanical property have been studied through thermogravimetric analysis (TGA) and compression testing. Depending on thermal stability and mechanical property, $30 / 70$ has been found to be the optimum A/R ratio. Microscopy is used for the structural and volumetric study of the capsules. To prove the effectiveness (healing efficiency) of the capsules in an asphalt mortar mix, capsules are embedded in asphalt mortar beams and a bending and healing program is carried out. To demonstrate that the improvement of healing is from the rejuvenator 
rather than the capsule shell material, blank capsules without rejuvenator are used as references in the bending and healing program.

\section{Experimental Method}

\subsection{Materials and Preparation}

\subsubsection{Capsule Preparation Process}

As shown in Figure 1, the rejuvenator (healing agent) within the capsule structure was created by calcium alginate crosslinks inside the calcium alginate capsules [16]. Firstly, 6 wt.\% sodium alginate solution was prepared in demineralized water. Then $2.5 \mathrm{wt} . \%$ solution of poly ethylene-alt-maleic-anhydride (PEMA) was mixed with the rejuvenator with a ratio of $40 \%$ PEMA and $60 \%$ healing agent, forming a healing agent solution. The PEMA was used to coat the rejuvenator and prevent the diffusion of rejuvenator into alginate shell. Subsequently, the sodium alginate solution and healing agent solution (rejuvenator and PEMA) were mixed. The sodium alginate and healing agent solution was prepared in varying A/R ratios: 100/0, 60/40, 50/50, 40/60, 30/70, 20/80 and $10 / 90$. To remove any trapped air in the blend, the blend was vacuumed in a vacuum chamber for 60 min. After that, the blend was pumped through a needle dropwise into the $\mathrm{CaCl}_{2}$ solution to allow capsule formation. The $\mathrm{CaCl}_{2}$ solution was stirred at a low speed for the full duration of the capsule production process. This process prevented capsules from amalgamating. After a full capsule batch was produced, capsules were drained from the $\mathrm{CaCl}_{2}$ bath and gently washed using demineralized water. Then the calcium alginate capsules were left to dry in a drying oven for $48 \mathrm{~h}$ at $30{ }^{\circ} \mathrm{C}$. Around $113.2 \mathrm{~g}$ of capsules can be produced based on $100 \mathrm{~g}$ of rejuvenator.

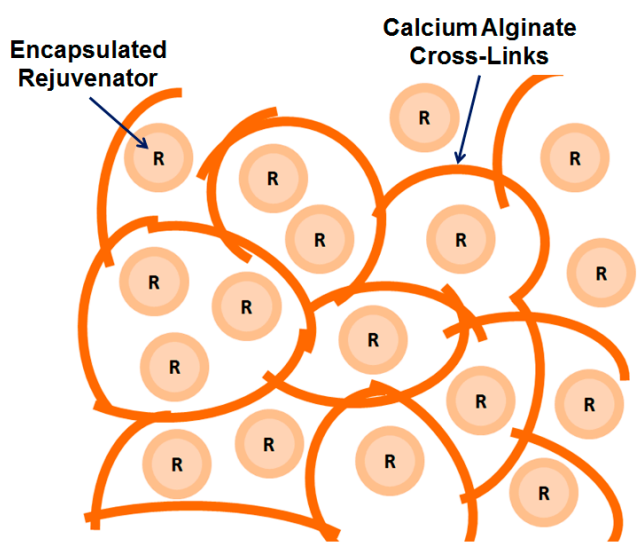

Figure 1. Rejuvenator encapsulated by the calcium alginate crosslinks.

The healing agent used in this research is an industrially produced asphalt rejuvenator ' $\mathrm{R} 20^{\prime}$ supplied from Latexfalt, Koudekerk aan den Rijn, Netherlands. All other chemicals used in the capsule preparation process were supplied from Sigma Aldrich, St. Louis, MO, USA.

\subsubsection{Asphalt Mortar Components}

According to a porous asphalt aggregate skeleton study, the bituminous mortar in the top layer of a porous asphalt mixture contains sand fractions smaller than $0.5 \mathrm{~mm}[19,20]$. Based on the RAW specification for porous asphalt [21], the mortar composition is derived. Two types of capsules were used in the mortar mix preparation, including capsules with rejuvenator (A/R ratio at 30/70) and blank capsules (A/R ratio at 100/0). As a result, three types of mortar mix were prepared, including the control mix (without capsules), $2.6 \mathrm{wt} . \%$ capsules mix and $2.6 \mathrm{wt} . \%$ blank capsules mix. The mix compositions of the asphalt mortar are shown in Table 1 . The sand used in this study is sieved from the Bestone sand, Bontrup, Amsterdam, Netherlands. The filler is type wigro 60k, which consists of 
25 35\% calcium hydroxide, provided from Bontrup, Amsterdam, Netherlands. The 70/100 bitumen was provided by Latexfalt, Koudekerk aan den Rijn, Netherlands.

Table 1. Mix composition of asphalt mortar.

\begin{tabular}{cccc}
\hline \multirow{2}{*}{ Mix Constituent } & \multicolumn{3}{c}{ Percentage by Weight } \\
\cline { 2 - 4 } & Without Capsules & $\mathbf{2 . 6 \%}$ Capsules & $\mathbf{2 . 6 \%}$ Blank Capsules \\
\hline Sand $<0.5 \mathrm{~mm}$ & 34.8 & 34.8 & 34.8 \\
Filler (Wigro60k) & 32.6 & 32.6 & 32.6 \\
Bitumen (70/100) & 32.6 & 30.0 & 30.0 \\
Capsules & 0 & 2.6 & 0 \\
Blank Capsules & 0 & 0 & 2.6 \\
\hline
\end{tabular}

Prior to mixing, all of the asphalt mix constituents were preheated in an oven for $2 \mathrm{~h}$ at $160{ }^{\circ} \mathrm{C}$. Then, sand, filler and bitumen were mixed using a Hobart Mixer forming a mortar. The capsules were gradually added to the mortar. Subsequently, the mortar mixture was compacted by a roller cylinder in a mold to form the beam test samples. The length, width and height of the beams are $125 \mathrm{~mm}$, $15 \mathrm{~mm}$ and $25 \mathrm{~mm}$, respectively. A ' $\mathrm{v}$ ' notch at the center of the beam was made during the casting process in order to achieve controlled crack propagation [16].

\subsubsection{Ageing on Asphalt Mortar Mix}

The aim of the capsule healing system is to achieve self-healing by restoring the lost properties of aged asphalt. The healing effect of the capsules is illustrated when applied in aged asphalt mixture. Hence, except the fresh mortar mix mentioned in Section 2.1.2, some aged asphalt mortar mix were prepared by ageing of the asphalt mortar mix based on a laboratory ageing procedure which was used by Shi et al. [16] and Tabaković et al. [15]: the asphalt mix was cured at $135^{\circ} \mathrm{C}$ for $4 \mathrm{~h}$ and then $85^{\circ} \mathrm{C}$ for 4 days.

\subsection{Characterization of Capsules}

The morphology of calcium alginate capsules was characterized using a Leica MZ 6 light microscope (Leica Microsystems B.V., Amsterdam, NetherlandsPhilips XL30 ESEM (Philips, Eindhoven, Netherlands) was employed to evaluate the microstructure inside the capsule. The ESEM was operated at $20 \mathrm{kV}$ accelerating voltage and the magnification was $1000 \times$. The scanning capsules were pre-coated with epoxy and polished until the cross sections were reached; in this way, the inner structure of capsules can be investigated by scanning the cross-sectional area using ESEM.

The temperature dependent mass changes of the calcium alginate capsules were evaluated with NETZSCH STA 449 F3 Jupiter TGA system (NETZSCH, Wormerveer, Netherlands). The analysis was performed in an argon (Ar) atmosphere. As shown in Figure 2, a temperature control program was employed, and the mass changes were recorded with time.

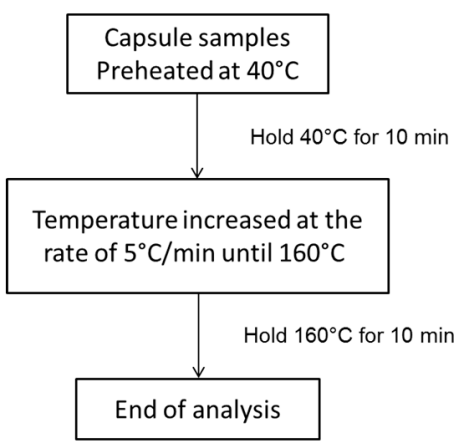

Figure 2. Thermogravimetric analysis (TGA) temperature control program. 
The mechanical resistance of the calcium alginate capsules was evaluated by compressive strength using a micro tensile strength testing machine (TSTM) developed by Microlab (Figure 3a) [16]. The tests were performed under $20^{\circ} \mathrm{C}$ with displacement control at a speed of $0.01 \mathrm{~mm} / \mathrm{s}$. A video camera was used to record the capsule deformation during the compression process. Prior to the compressive test, capsules were cured for $15 \mathrm{~min}$ at 10 different temperatures $\left(\right.$ at $20^{\circ} \mathrm{C}$ increments from $-20{ }^{\circ} \mathrm{C}$ to $160^{\circ} \mathrm{C}$ ) to study the mechanical property of capsules considering the multi-temperature effect. At least five capsules were studied for each condition.

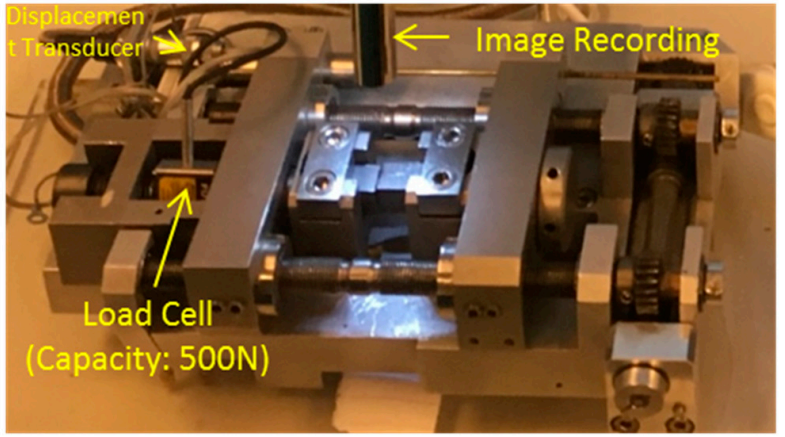

a

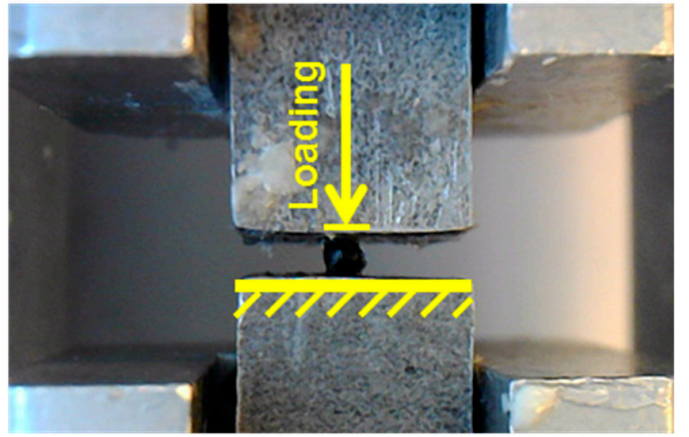

b

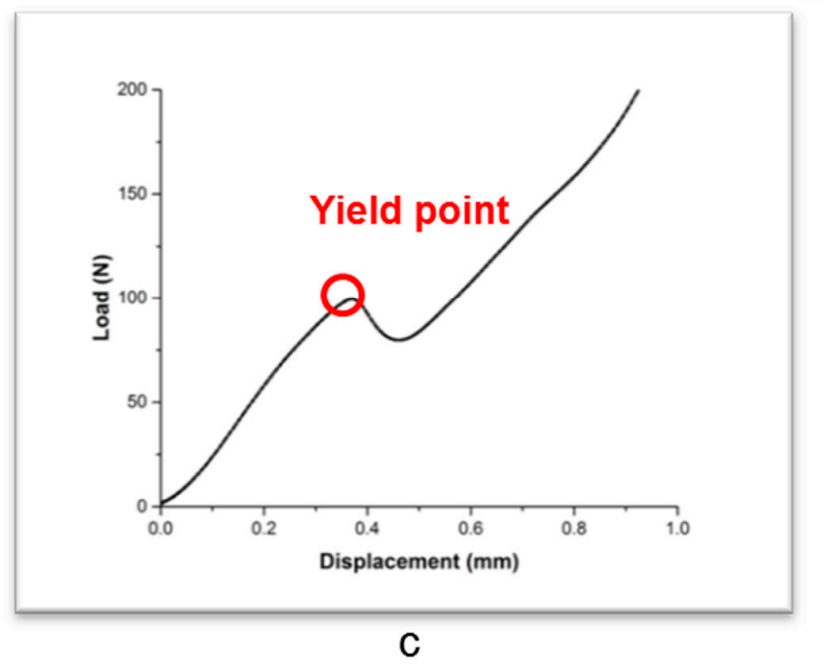

Figure 3. Compressive test on calcium alginate capsules using tensile strength testing machine (TSTM): (a) TSTM testing setup; (b) a capsule sample during compression; and (c) a load and displacement curve from compressive test.

In this research, the yield strength of the tested capsule (Figure 3b) was used as the compressive strength. Below this yield point (see Figure 3c) a capsule showed elastic behavior. When the stress went higher, permanent deformation was created and the capsule gradually ruptured, along with a leaking out of the rejuvenator.

\subsection{Three-Point-Bending Test and the Healing Efficiency of the Asphalt Mortar}

The 3PB test was chosen to determine the healing efficiency of the calcium alginate capsules on the asphalt mortar. By using a Universal Testing Machine (UTM) (Industrial process controls LTD, Melbourne, Australia). The 3PB tests were performed at the loading speed of $0.01 \mathrm{~mm} / \mathrm{s}$ under $-10^{\circ} \mathrm{C}$ to create a brittle fracture in the mortar sample. The beam height, support span and beam width used in this study are $25 \mathrm{~mm}, 100 \mathrm{~mm}$ and $15 \mathrm{~mm}$, respectively. During 3PB tests, the notch allowed cracks to initiate at the center of the beams and propagating throughout the cross section of the beams. 
The healing efficiency of these asphalt mortar beams was evaluated through a bending and healing program. At first, 3PB tests were performed to allow crack formation and acquire the initial strength of beam specimens. Then, the fractured beams were healed back in the mold at $20^{\circ} \mathrm{C}$ for $4 \mathrm{~h}$ and followed by $3 \mathrm{~PB}$ tests to acquire the bending strength after the first healing. Subsequently, the fractured beams were healed again for $12 \mathrm{~h}$ in the mold and followed by another 3PB test to acquire the bending strength after second healing.

The Healing Index (HI) was used to characterize the healing efficiency, which was calculated using the formula below [16]:

$$
\mathrm{HI}=\frac{\mathrm{C}_{\mathrm{x}}}{\mathrm{C}_{1}} \times 100 \%
$$

where $\mathrm{HI}$ is the healing index of asphalt mortar beam, $\mathrm{C}_{1}$ is original bending strength (MPa) of the beam sample and $\mathrm{C} x$ is the bending strength (MPa) after $\mathrm{x}$ cycles of healing.

\section{Results and Discussion}

\subsection{Capsule Morphology}

Figure 4 presents the optical images of the capsule with different A/R ratios. Without rejuvenator, the calcium alginate capsule has a transparent brown color and ellipsoid shape.

With encapsulated rejuvenator, the calcium alginate capsules become black, and increasing the amount of rejuvenator results in a more spherical morphology. Table 2 summarizes the diameter and morphology information of capsules fabricated with different $A / R$ ratios. At least 12 capsules were measured for each $A / R$ ratio type and since the well-controlled manufacture process, the capsules had the same diameters for each $\mathrm{A} / \mathrm{R}$ ratio type. The results indicate that the diameter of capsules increases with rejuvenator content. When the $\mathrm{A} / \mathrm{R}$ ratio is beyond $40 \%$, the fabricated capsules become ellipsoids. This change in morphology might be due to dehydration of the hydrated alginate. During the drying process, higher alginate content would result in more dehydration and greater deformation.

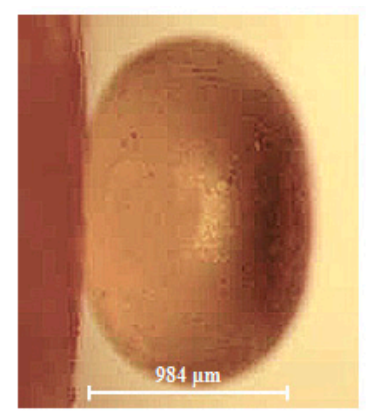

$\mathrm{A} / \mathrm{R}=100 / 0$

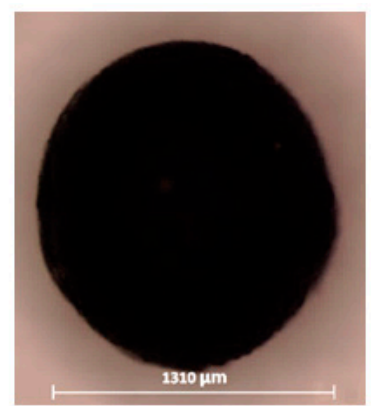

$\mathrm{A} / \mathrm{R}=50 / 50$

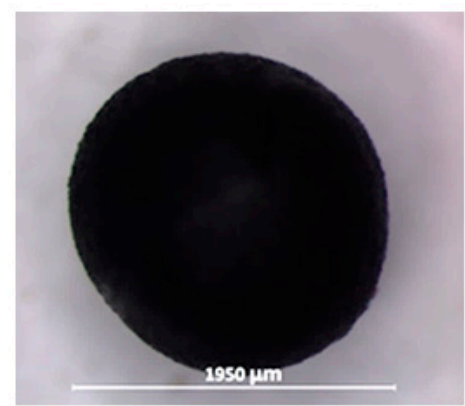

$\mathrm{A} / \mathrm{R}=30 / 70$

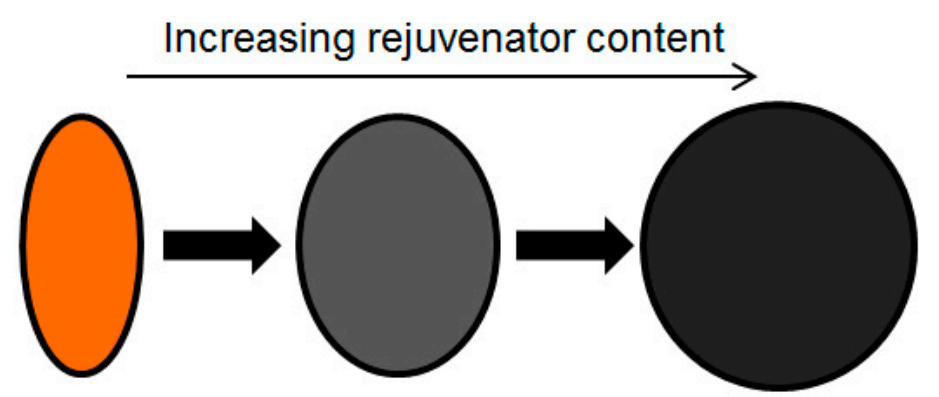

Figure 4. Microscopic images of capsules and the trend with alginate/rejuvenator (A/R) ratio. 
Table 2. Calcium alginate capsules with different alginate/rejuvenator ratios.

\begin{tabular}{cccc}
\hline Alginate/Rejuvenator Ratio $(\%)$ & Diameter $(\mu \mathrm{m})$ & Minor Axis $(\mu \mathrm{m})$ & Morphology \\
\hline $100 / 0$ & 1500 & 980 & \\
$60 / 40$ & 1920 & 1670 & Ellipsoid \\
$50 / 50$ & 1640 & 1310 & \\
$40 / 60$ & 1740 & 1600 & \\
$30 / 70$ & 1950 & 1950 & Sphere \\
$20 / 80$ & 2170 & 2170 & \\
$10 / 90$ & 2450 & 2450 & \\
\hline
\end{tabular}

\subsection{Capsule Microstructure}

The cross-sectional ESEM images of capsules fabricated with A/R ratios of 60/40, 50/50, 40/60, $30 / 70,20 / 80$ and 10/90 are shown in Figure 5. In these images, the bright pixels are recognized as alginate, while the rest are rejuvenator. These ESEM images indicate an existence of alginate network inside of the capsules, which means the capsules have the rejuvenator encapsulated in the porous media instead of the traditional capsule' core-shell structure. From the image in Figure 5a to Figure 5f, an increasing rejuvenator volume and decreasing alginate network can be seen, which matches the applied amount of rejuvenator in each capsule.
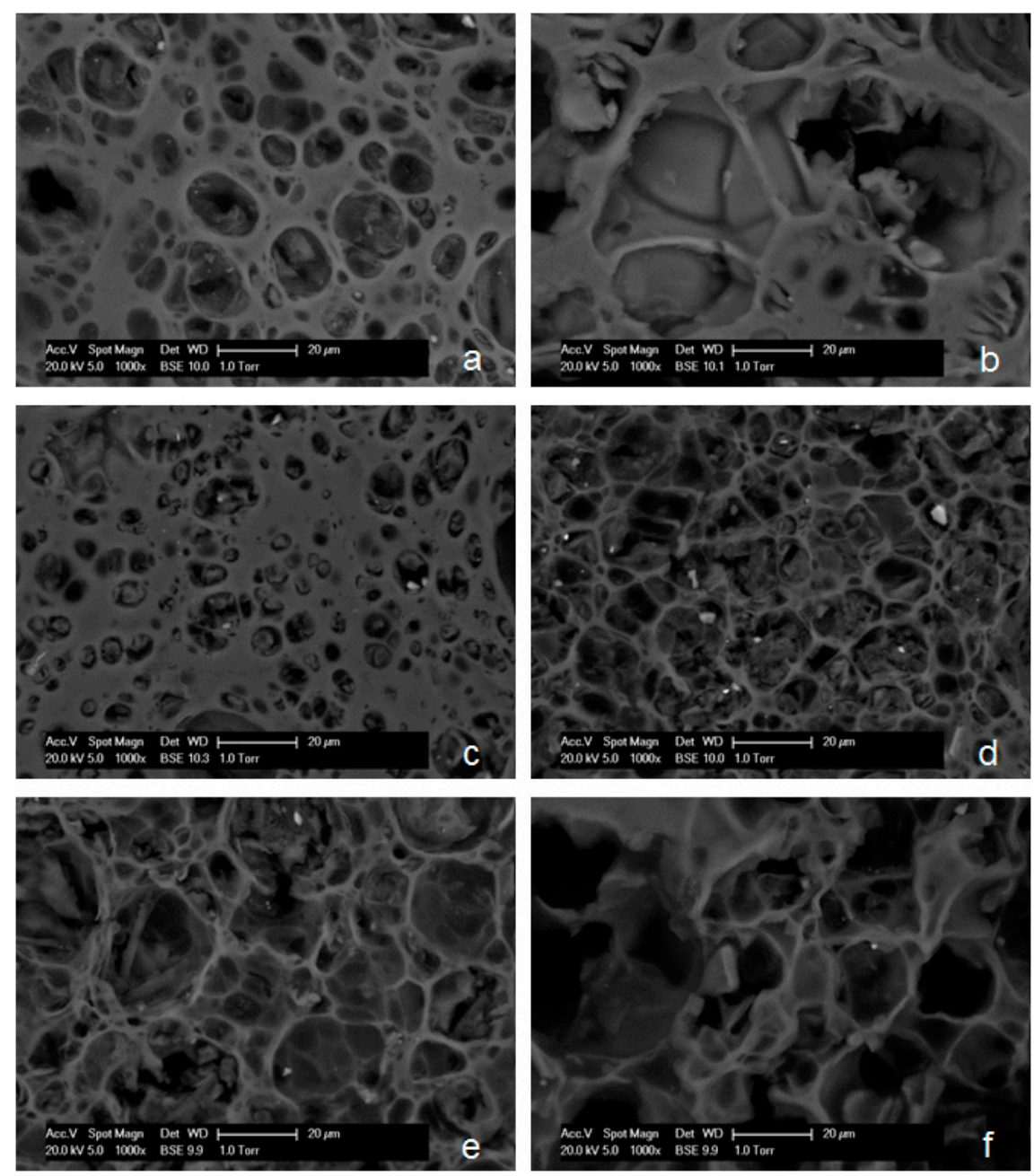

Figure 5. The cross-sectional ESEM images of calcium alginate capsules fabricated with A/R ratios of: (a) 60/40, (b) 50/50, (c) 40/60, (d) 30/70, (e) 20/80 and (f) 10/90. 
As stated in the previous research [16], this honeycomb-like structure provides a structural reinforcement that allows the capsule to possess higher thermal and mechanical resistance. Meanwhile, the compartmented rejuvenator storage in porous media could even have multi-healing function on micro cracks.

\subsection{Thermogravimetric Analysis}

Figure 6 shows the TGA results for capsules fabricated with varying A/R ratios. When the testing temperature is below $100{ }^{\circ} \mathrm{C}$ (before $25 \mathrm{~min}$ ), all of the capsules show less than $2 \%$ weight loss. When the testing temperature exceeds $100^{\circ} \mathrm{C}$, linear increasing weight loss trends can be observed for capsules with different $A / R$ ratios. Weight loss of capsules in this region is most likely due to the dehydration of calcium alginate gels. Among all the analyzed capsules, capsules with an A/R ratio of 10/90 show the lowest weight loss during the tests, and the weight loss trend increases with the alginate contents. As the temperature reaches $160^{\circ} \mathrm{C}$ (referred as the asphalt mixing temperature) and is held for $15 \mathrm{~min}$, the weight loss of the capsules retains a linear trend, and the final weight loss percentages of capsules with A/R ratios of $60 / 40,50 / 50,40 / 60,30 / 70,20 / 80$ and $10 / 90$ are $10.5 \%$, $7.9 \%, 5.6 \%, 4.9 \%, 3.8 \%$ and $2.2 \%$, respectively. This indicates that the capsules, except surface moisture evaporation, do not experience any significant degradation at $160^{\circ} \mathrm{C}$. Meanwhile, when the A/R ratio is lower than $40 / 60$, the final weight loss is lower than $5 \%$, which means capsules with these ratios are relatively more stable and are capable of surviving the asphalt mixing temperature.



Figure 6. TGA results of capsules fabricated with varying A/ $R$ ratios.

\subsection{Compressive Tests on Capsules}

Figure 7 shows the compressive testing results for different $\mathrm{A} / \mathrm{R}$ ratios of capsules. In general, with the increase of curing temperature, especially from $100{ }^{\circ} \mathrm{C}$ to $160{ }^{\circ} \mathrm{C}$, a decrease of compressive strength can be found. It can also be seen that higher rejuvenator content results in lower compressive strength on capsules, especially under higher curing temperatures. The compressive testing results indicate that the dehydration of the alginate gel results in degradation of some of the calcium alginate chains and a decrease in the compressive strength of calcium alginate capsules.

The corresponding compression for the mastic mix is about $1.8 \mathrm{MPa}$, and the vehicle loading pressure is less than $1 \mathrm{MPa}[22,23]$. After curing at $160{ }^{\circ} \mathrm{C}$, capsules with $\mathrm{A} / \mathrm{R}$ ratios of $20 / 80$ and 
10/90 show a compressive strength less than 0.4 MPa, which is insufficient to survive the asphalt production process. Meanwhile, for the capsules with a ratio of 30/70, at the curing temperature of $160{ }^{\circ} \mathrm{C}$, the lowest compressive strength in the curve remains $3.27 \mathrm{MPa}$. Hence, the capsules fabricated with $\mathrm{A} / \mathrm{R}$ ratio of $30 / 70$ are expected to show elastic behavior and survive the asphalt mixing process and dynamic vehicle loading during the asphalt pavement service life. Although capsules with other $\mathrm{A} / \mathrm{R}$ ratios also have applicable compressive strength, they contain less rejuvenator. According to the compressive tests as well as the TGA test results, $30 / 70$ is determined to be the optimum A/R ratio.

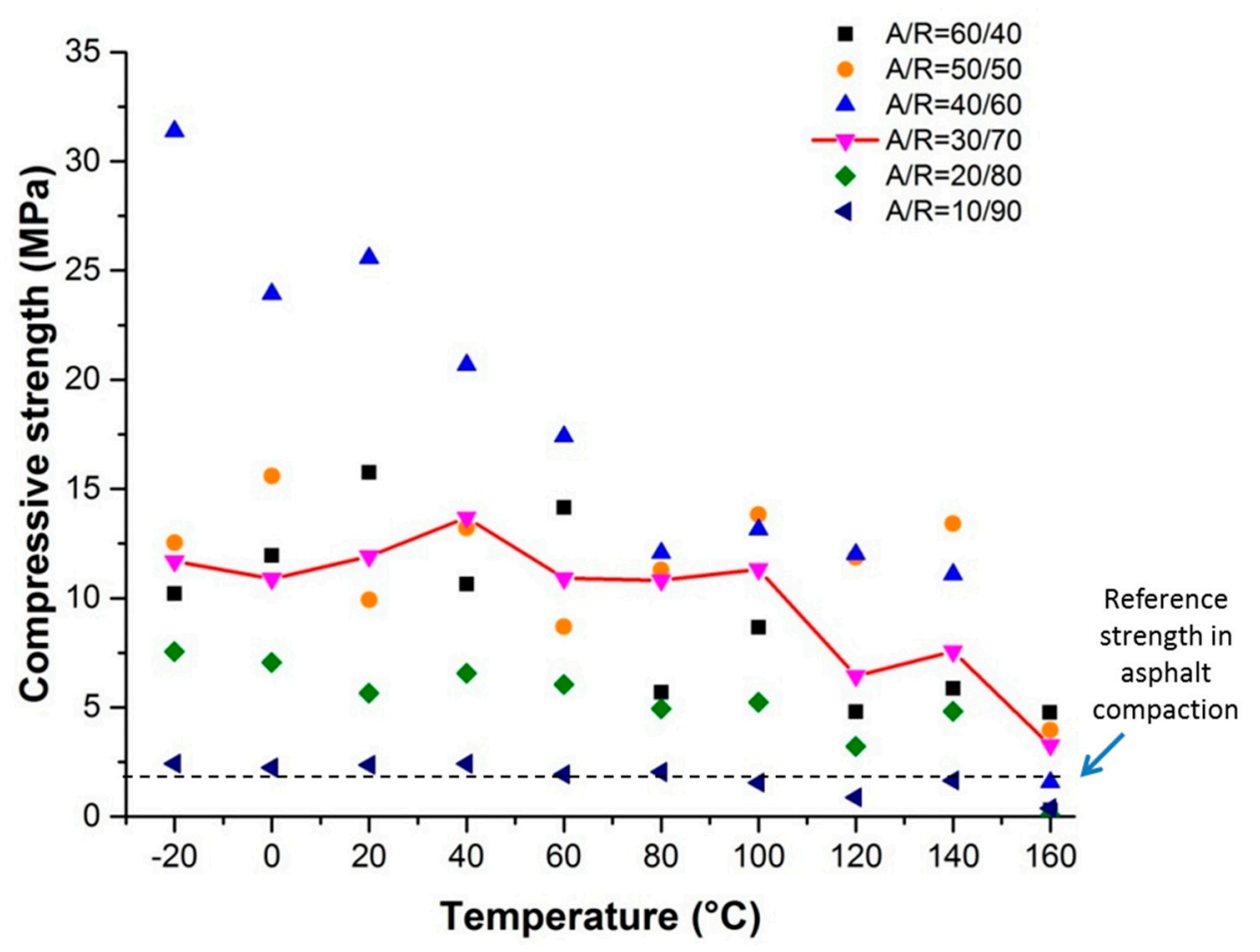

Figure 7. Compressive strength of capsules fabricated with varying $A / R$ ratios cured under different temperatures.

\subsection{PB Tests}

Calcium alginate capsules prepared with the optimum A/R ratio $(30 / 70)$ were applied in the asphalt mortar mix. Figure 8 shows the bending strength of the asphalt mortar beams made with fresh material. As shown in Figure 8, for all mortar beam types, the bending strength decreases after each bending and healing cycle, which indicates that the self-healing effect of the asphalt mortar beams cannot achieve full recovery of strength since the fractured area is prone to crack even after the healing process. During each testing cycle, the bending strengths of all three types of beams are very similar, and the mortar beams still have strengths about $4 \mathrm{MPa}$ after 2 testing cycles, even without capsules or with blank capsules. This means that the healing capacity of the fresh material itself plays the main role in crack healing (strength recovery). It also demonstrates that the presence of calcium alginate capsules, containing rejuvenator or not, does not significantly affect the initial bending strength of the mortar beams. Hence, when the bituminous material possesses sufficient healing capacity, like in fresh bitumen, the capsule healing system could hardly improve the healing efficiency. 


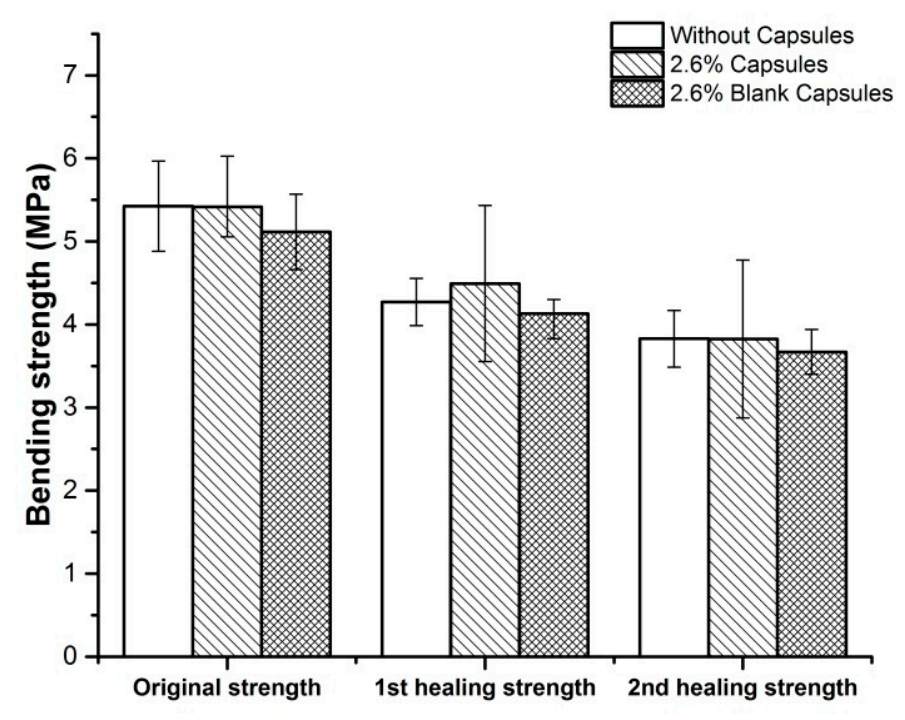

Figure 8. Bending strength of asphalt mortar beams.

Ageing of the asphalt mixture could not only increase its stiffness, but also decrease its healing capacity. As shown in Figures 8 and 9a, without capsules, the initial bending strength of aged asphalt mortar beams is $4.7 \mathrm{MPa}$, which is lower than the strength of fresh ones (5.4 MPa). This indicates that the laboratory ageing process decreases the bending strength of asphalt mortar beams. Figure 9 shows that after ageing, the asphalt mortar mix loses most of its healing capacity as the mortar beams without capsules only regain a strength of $0.2 \mathrm{MPa}$ ( $4 \%$ of the original strength) during the first healing period. Nevertheless, with calcium alginate capsules encapsulating rejuvenator, the beams recover a strength of $1.7 \mathrm{MPa}(40 \%$ of the original strength) during first healing (Figure $9 \mathrm{~b}$ ). This might be because the ageing of asphalt mortar greatly decreases its healing capacity, and the aged material could not provide a sufficient bond between the fracture surfaces. However, with capsules, the encapsulated asphalt rejuvenator can be released when the crack propagates through the capsules which allows localized healing around the broken capsules on the fracture surfaces. Thus, more strength can be regained during the healing process on mortar beams with capsules.
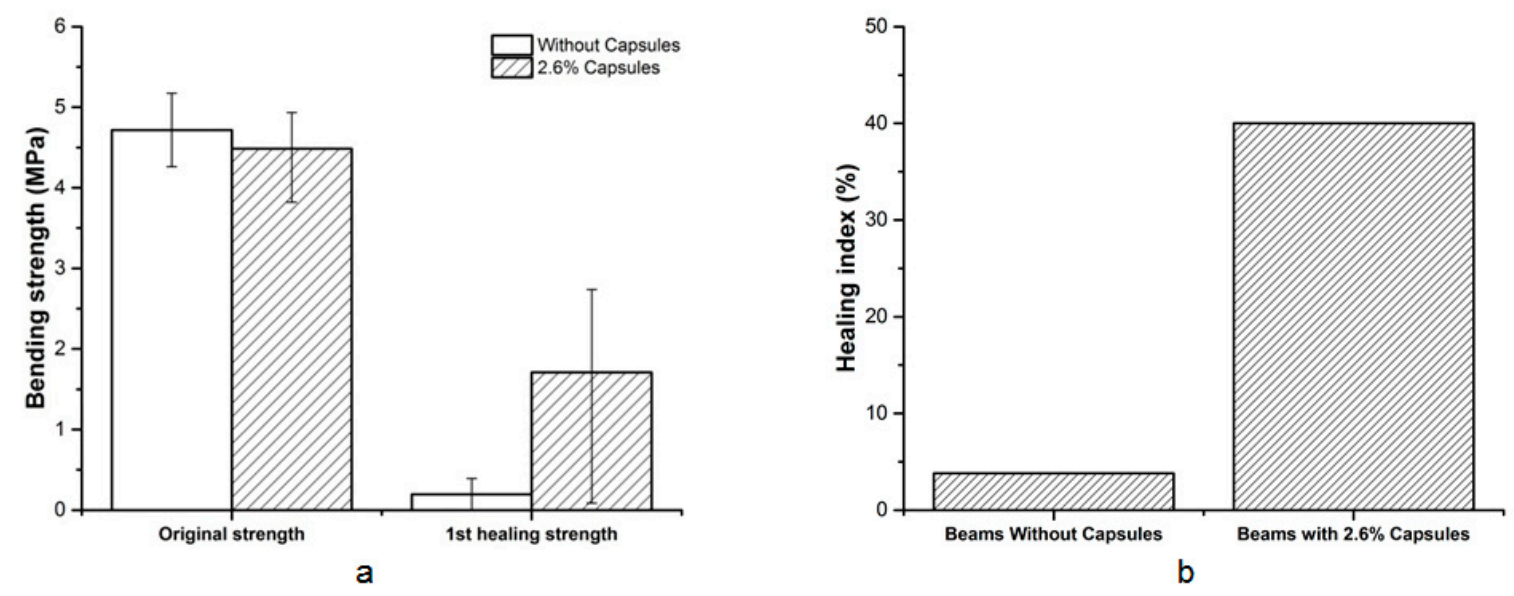

Figure 9. Testing of aged asphalt mortar beams in bending and healing program: (a) Bending strength and (b) healing efficiency.

\section{Conclusions}

In this study, the thermal and mechanical properties of the prepared calcium alginate capsules for self-healing asphalt applications have been studied and optimized by changing the A/R ratio. 
The bending tests on asphalt mortar samples further demonstrate the healing mechanism of the calcium alginate capsules healing system. The following conclusions can be drawn:

- The $\mathrm{A} / \mathrm{R}$ ratios used in the capsule production process greatly influence the morphology, structure and performance of calcium alginate capsules. In principle, a higher rejuvenator content (lower A/R ratio) results in a larger diameter, larger inside pores, higher thermal resistance and less compressive strength;

- The optimum A/R ratio is 30/70, as the prepared capsules not only have sufficient thermal and mechanical resistance to survive the asphalt mixing and compaction process, but also contain as much rejuvenator as possible;

- The asphalt mortar beams with capsules, with blank capsules and without capsules demonstrated similar bending strengths for all testing cycles, which indicates that the intrinsic healing capacity of the asphalt mortar is relatively high and plays the main role in the healing process of asphalt mortar samples;

- The asphalt mortar beams with blank capsules do not showed significant difference initial bending strength than the other two mixes, which means calcium alginate, the encapsulation material of these capsules, hardly has any contribution to the bending strength of asphalt mortar beams;

- In the aged asphalt mortar beams, the samples with capsules showed a healing index of $40 \%$, which is much higher than those without capsules (4\%). This indicates that the encapsulated asphalt rejuvenator can be released upon cracking and rejuvenate the aged material to heal the crack.

The ultimate goal of self-healing asphalt is to produce a road that possesses autonomic healing ability, greatly prolonging its service life. Optimization of the calcium alginate capsules healing system helps the development of this self-healing technology and moves one step closer to this goal.

Author Contributions: S.X., A.T., X.L., D.P. and E.S. conceived and designed the experiments; S.X. performed the experiments and analyzed the data; S.X. wrote the paper; A.T., X.L., D.P. and E.S. reviewed the paper.

Acknowledgments: The authors would like to acknowledge the scholarship from the China Scholarship Council (No. 201506950066). The authors also wish to thank Bert Jan Lommerts, Irina Catiugă and Sayeda Nowrozon Nahar, Latexfalt BV, for their support to the project. In addition, the technicians from Microlab and the Section of Pavement Engineering of TU Delft are greatly appreciated for their technical support.

Conflicts of Interest: The authors declare no conflict of interest.

\section{References}

1. Airey, G.D. State of the art report on ageing test methods for bituminous pavement materials. Int. J. Pavement Eng. 2003, 4, 165-176. [CrossRef]

2. Pasetto, M.; Baldo, N. Fatigue performance of asphalt concretes with RAP aggregates and steel slags. In 7th RILEM International Conference on Cracking in Pavements; Springer: Dordrecht, The Netherlands, 2012; pp. 719-727.

3. Morea, F.; Zerbino, R. Improvement of asphalt mixture performance with glass macro-fibers. Construct. Build. Mater. 2018, 164, 113-120. [CrossRef]

4. Sun, Y.; Fang, C.; Wang, J.; Yuan, X.; Fan, D. Method of Fatigue-Life Prediction for an Asphalt Mixture Based on the Plateau Value of Permanent Deformation Ratio. Materials 2018, 11, 722. [CrossRef] [PubMed]

5. Xu, S.; García, A.; Su, J.; Liu, Q.; Tabaković, A.; Schlangen, E. Self-Healing asphalt review: From idea to practice. Adv. Mater. Interf. 2018, 5, 1800536. [CrossRef]

6. Shirzad, S.; Hassan, M.M.; Aguirre, M.A.; Mohammad, L.N.; Cooper, S.; Negulescu, I.I. Microencapsulated Sunflower Oil for Rejuvenation and Healing of Asphalt Mixtures. J. Mater. Civ. Eng. 2017, 29, 04017147. [CrossRef]

7. Tabaković, A.; Schlangen, E. Self-healing technology for asphalt pavements. Self-Healing Mater. 2016, $285-306$.

8. Xiao, F.; Yao, S.; Wang, J.; Li, X.; Amirkhanian, S. A literature review on cold recycling technology of asphalt pavement. Construct. Build. Mater. 2018, 180, 579-604. [CrossRef] 
9. Wang, F.; Wang, Z.; Li, C.; Xiao, Y.; Wu, S.; Pan, P. The rejuvenating effect in hot asphalt recycling by mortar transfer ratio and image analysis. Materials 2017, 10, 574. [CrossRef] [PubMed]

10. Ayar, P.; Moreno-Navarro, F.; Rubio-Gámez, M.C. The healing capability of asphalt pavements: A state of the art review. J. Cleaner Prod. 2016, 113, 28-40. [CrossRef]

11. White, S.R.; Sottos, N.R.; Geubelle, P.H.; Moore, J.S.; Kessler, M.; Sriram, S.R.; Brown, E.N.; Wiswanathan, S. Autonomic healing of polymer composites. Nature 2001, 409, 794. [CrossRef] [PubMed]

12. García, Á.; Schlangen, E.; Van de Ven, M. Properties of capsules containing rejuvenators for their use in asphalt concrete. Fuel 2011, 90, 583-591. [CrossRef]

13. Su, J.; Qiu, J.; Schlangen, E. Stability investigation of self-healing microcapsules containing rejuvenator for bitumen. Polym. Degrad. Stab. 2013, 98, 1205-1215. [CrossRef]

14. Prajer, M.; Wu, X.; Garcia, S.J.; van der Zwaag, S. Direct and indirect observation of multiple local healing events in successively loaded fibre reinforced polymer model composites using healing agent-filled compartmented fibres. Compos. Sci. Technol. 2015, 106, 127-133. [CrossRef]

15. Tabaković, A.; Post, W.; Cantero, D.; Copuroglu, O.; Garcia, S.; Schlangen, E. The reinforcement and healing of asphalt mastic mixtures by rejuvenator encapsulation in alginate compartmented fibres. SmMaS 2016, 25, 084003. [CrossRef]

16. Xu, S.; Tabaković, A.; Liu, X.; Schlangen, E. Calcium alginate capsules encapsulating rejuvenator as healing system for asphalt mastic. Construct. Build. Mater. 2018, 169, 379-387. [CrossRef]

17. Xu, S.; Liu, X.; Tabaković, A.; Schlangen, E. Investigation of the Potential Use of Calcium Alginate Capsules for Self-Healing in Porous Asphalt Concrete. Mater. 2019, 12, 168. [CrossRef]

18. Draget, K.I.; Skjåk-Bræk, G.; Smidsrød, O. Alginate based new materials. Int. J. Biol. Macromol. 1997, 21, 47-55. [CrossRef]

19. Muraya, P.M. Permanent Deformation of Asphalt Mixes; Delft University of Technology: Delft, The Netherlands, 2007.

20. Woldekidan, M.F. Response Modelling of Bitumen, Bituminous Mastic and Mortar; Delft University of Technology: Delft, The Netherlands, 2011.

21. CROW, I. Standaard RAW Bepalingen; CROW: Ede, The Netherlands, 2005.

22. Brown, E.R.; Kandhal, P.S.; Zhang, J. Performance Testing for Hot Mix Asphalt; National Center for Asphalt Technology at Auburn University': Auburn, AL, USA, 2001.

23. Tabaković, A.; Karač, A.; Ivanković, A.; Gibney, A.; McNally, C.; Gilchrist, M.D. Modelling the quasi-static behaviour of bituminous material using a cohesive zone model. Eng. Fract. Mech. 2010, 77, 2403-2418. [CrossRef]

(C) 2019 by the authors. Licensee MDPI, Basel, Switzerland. This article is an open access article distributed under the terms and conditions of the Creative Commons Attribution (CC BY) license (http:/ / creativecommons.org/licenses/by/4.0/). 